\title{
Cooperation with demand characteristics and the bimodal distribution of verbal conditioning data
}

\author{
MONTE M. PAGE AND AUGUSTUS R. LUMIA DEPARTMENT \\ OF PSYCHOLOGY, UNIVERSITY OF NEBRASKA, Lincoln, \\ Nebr. 68508
}

A frequency distribution of verbal conditioning data was found to be quite bimodal. The upper mode was populated exclusively with Ss who claimed to have been aware of and cooperating with demand characteristics during the experiment. Contrary to expectations, $S$ sophistication (time of semester) did not significantly increase verbal conditioning. Postexperimental estimates by aware and cooperating $S$ s as to the point at which they became aware correlated highly with the point at which they first showed a decided preference for reinforced pronouns.

In two previous studies (Page, 1968; Page, submitted), data were found to be strikingly bimodal. Some Ss responded maximally in the direction of the E's hypothesis while the rest as a group appeared to be little affected. In both of these studies the upper mode of the distribution was populated exclusively by Ss who, upon careful postexperimental questioning, reported having been aware of correct experimental demand characteristics (Orne, 1962) and cooperating with them. The lower portion of the data was populated mostly by Ss who were unable to report the E's hypothesis or who knew the hypothesis but reported rather deliberate attempts not to cooperate with it. Because of these clear cut results, it was suggested that perhaps the bimodal distribution of data obtained in some other experimental settings also reflected Ss aware and cooperating with demand characteristics.

It has long been noted that verbal conditioning procedures produce high within-S's variance (Greenspoon, 1962). The primary purpose of this study was to examine this within-S variance in terms of awareness of and cooperation with demand characteristics. It was predicted that the frequency distribution of Ss conditioning scores would be bimodal and that Ss located in the upper mode would be those who could report what the E's hypothesis was and that they had known this during the experiment and had cooperated with it. Also, since S sophistication was found to be a significant variable previously, it was again manipulated in this study. It was expected that sophisticated Ss (end of the semester) would verbally condition more than naive Ss (first of the semester).

Subjects

The Ss were 150 introductory psychology students. Thirty Ss were assigned to a control group. Of the experimental Ss, 60 were run during the first three weeks of the semester (naive) and 60 were run during the last three weeks (sophisticated). Introductory students were expected to participate in experiments, but were allowed to choose the studies they served in. This is a deviation from previous procedure where Ss were assigned randomly to early or late participation.

Procedure

The task and instructions were of the standard Taffel (1955) type of verbal conditioning procedure. One hundred cards each containing a past tense verb with six pronouns in random order below it were used. The $E$ sat behind a plywood shield and presented the cards through an aperture. After 20 base line trials, the $E$ began reinforcing each use of either the pronouns $I$ or WE with a simple "good." No extinction trials were given so as not to confound the results of the postexperimental inquiry. The control group was given random reinforcement on an average of every 3 rd trial. Experimental group $S s$ were introduced to the postexperimental questionnaire with orienting instructions similar to those used previously (Page, 1968). Then half of the Ss were given a written, and the other half an oral tape recorded interview to explore possible differences in mode of interviewing.
Results

Data were scored in the standard blocks of 20 trials manner. A 5 groups by 5 blocks analysis of variance was performed on these data. There was a significant blocks effect $(F=51.71$, $\mathrm{df}=4,580$; $\mathrm{p}<.001$ ) indicating an increase of I-WE pronouns over trials. The contrast between the control group and the four experimental groups was significant $(\mathrm{F}=12.55, \mathrm{df}=1,145 ; \mathrm{p}<.01)$ indicating that verbal conditioning did occur. The contrast between the sophisticated and naive groups was not significant $(\mathrm{F}=2.27 \mathrm{df}=$ 1,145 ; NS). Contrary to expectations, first of the semester Ss performance was not significantly less than that at the end of the semester, though the slight mean differences that did occur were in the predicted direction.

The Ss submitted to an oral interview were compared nonparametrically in a number of ways with those given a written interview. None of the comparisons were significantly different indicating that the two types of interviews used in this study lead to equivalent results. Consequently, these two groups were pooled for further analysis.

The postexperimental interviews were scored for (1) contingency awareness (did $S$ know that $E$ 's reinforcement was contingent upon I or WE pronouns); (2) demand awareness (did S believe that $E$ was trying to increase use of I or WE pronouns); and (3) cooperation (did S claim to have cooperated with E's hypothesis rather than resist). The senior author did this scoring without knowledge of the conditioning scores. The type of extended interview and scoring procedure is described elsewhere (Page, submitted). It was not considered necessary to have another judge score these protocols to check for interjudge reliability because in previous studies using this scoring technique the interjudge reliability was very high.

Figure 1 presents the frequency distribution of conditioning scores on the last block of 20 trials for the various subgroups derived from the postexperimental interview. The data is clearly bimodal. Of the $30 \mathrm{Ss}$ who had a conditioning score of 19-20 on

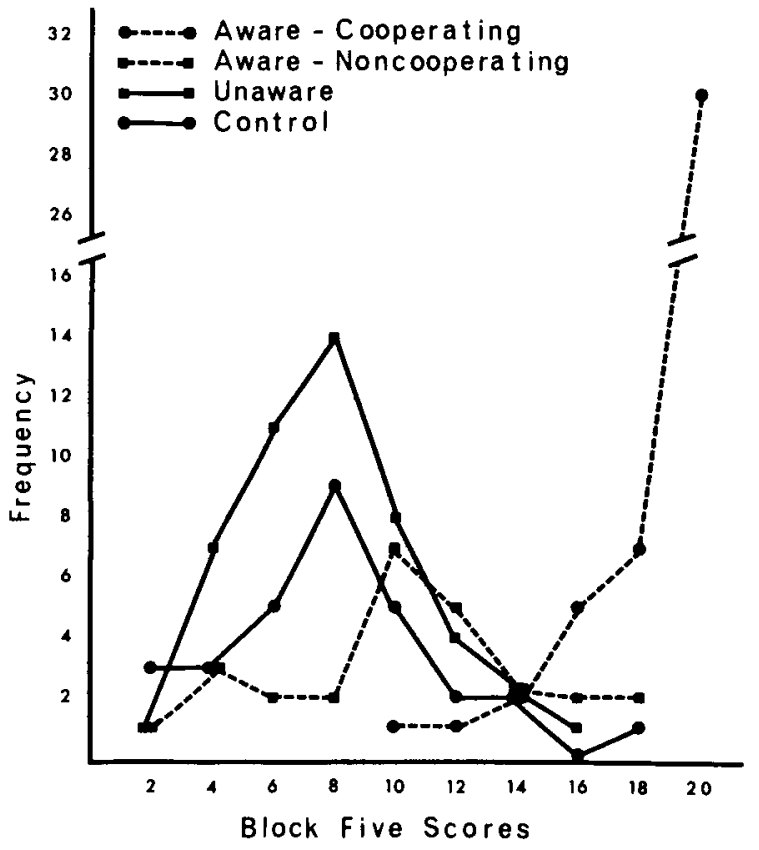

Fig. 1. Frequency distribution of I or WE responses on the fifth block of 20 trials for Ss grouped on the basis of demand awareness and cooperation. 
Table 1

Summary of Phi Coefficients (Over their Appropriate Phi-Max Values) of Association Between Four Dichotomized Variables

\begin{tabular}{|c|c|c|c|}
\hline & 2 & 3 & $\underline{4}$ \\
\hline $\begin{array}{l}\text { 1. Verbal } \\
\text { Conditioning }\end{array}$ & $\frac{.62}{1.00}$ & $\frac{.63}{.92}$ & $\frac{.83}{.98}$ \\
\hline $\begin{array}{l}\text { 2. Contingency } \\
\text { Awareness }\end{array}$ & & $\frac{.90}{.92}$ & $\frac{.64}{.96}$ \\
\hline $\begin{array}{l}\text { 3. Demand } \\
\text { Awareness }\end{array}$ & & & \\
\hline $\begin{array}{l}\text { 4. No. } 3 \text { plus } \\
\text { Cooperation }\end{array}$ & & & \\
\hline
\end{tabular}

the last block of 20 trials, every single one of them claimed to have known during the experiment that the $\mathrm{E}$ was attempting to reinforce (many actually used this language) I or WE pronouns, and they further claimed to have cooperated with this influence. Without this group of demand aware and cooperating $S s(N=46)$, the upper mode of the bimodal distribution would not exist. These data are similar to the senior author's previous data and lend further support to the contention that bimodal data may be one clue to the existence of demand characteristics artifacts in experimental data. Notice also the large number of $\mathrm{Ss}(\mathrm{N}=26)$ who knew the experimenter's hypothesis, but for various reasons refused to go along with it. This is the highest proportion of resistors yet to be found in our studies of demand characteristics, and it occurs along with a higher total proportion (60\%) of awares. Note also that the distribution of the unaware group $(N=48)$ is very similar to that of the control group. This is just what would be expected if the E's reinforcements meant no more to them than the random reinforcements meant to the control group.

Table 1 presents tests for association (phi coefficients) between the verbal conditioning and the various measures of awareness. The awareness data and the last block conditioning scores (15 or $>$ vs 14 or $<$ ) were dichotomized for this analysis. It may be seen that the best correlate with conditioning is demand awareness plus motivation to cooperate. These relationships are similar to those found in a study of attitude conditioning (Page, submitted).

The last question of the interview asked aware cooperating Ss to estimate the point during the 100 trials that they became aware of l or WE being the correct response. Conditioning records were then scored as to the point in the data where $S$ first began showing a decided preference ( 5 out of 6 trials) for reinforced pronouns. The correlation between these two scores was $\mathrm{r}=+.76(\mathrm{p}<.001$, $\mathrm{d} f=44$ ). The mean trial of estimated awareness was 46 while the mean trial of beginning of actual increase was 51 . These data suggest that awareness was not evoked by the postexperimental questions as some defenders of an S-R interpretation of verbal conditioning have claimed. If anything, The S's reports indicate that awareness slightly preceded behavioral change. This is consistent with reports by many Ss that they first discovered the correct contingency, then checked the other pronouns to see if any others would elicit reinforcement, then returned to consistent use of the reinforced pronouns. These data are consistent with Spielberger \& De Nike's (1966) interpretation of awareness and conditioning.

Discussion

Subject sophistication was not significant in this study. This was unexpected, since the senior author had twice before found it to be significant in studies where the data were also largely an artifact of demand characteristics. Also Holms (1967) had found that a large amount of experience in previous experiments, which is a similar but probably more potent variable, did increase verbal conditioning. Since the proportion of aware Ss in the present study was considerably higher than in previous studies where $S$ sophistication was significant, it may be that $S$ sophistication is likely to have more facilitating effect in those situations where the demand characteristics are relatively difficult to correctly perceive. In a situation like verbal conditioning which is relatively simple and repetetive, and elementary knowledge of psychology does not give a significant advantage in correctly perceiving the demand characteristics. It might be that if the verbal conditioning situation were made more difficult, there would be less overall awareness and a difference between sophisticated and naive groups.

The bimodal distribution of verbal conditioning data and the clear partitioning of these modes on the basis of assessment of demand awareness and cooperation lends credence to the contention that (at least in this specific situation) verbal conditioning is a pure artifact of demand characteristics. Or, as Holms (1967) has suggested, it is more appropriately termed a matter of problem solving and cooperation than it is conditioning. From S's point of view, the problem is to discover what $E$ wants.

\section{REFERENCES}

GREENSPOON, JOEL Verbal conditioning and clinical psychology. In A. J. Bachrach (Ed.), Experimental foundations of clinical psychology. New York: Basic Books, Inc., 1962.

HOLMES, D. S. Amount of experience in experiments as a determinant of performance in later experiments. J. Pers. Soc. Psychol., 1967, 7, 403-407.

ORNE, M. T. On the social psychology of the psychological experiment: With particular reference to demand characteristics and their implications. Amer. Psychologist, 1962, 17, 776-783.

PAGE, M. M. Modification of figure-ground perception as a function of awareness of demand characteristics. J. Pers. Soc. Psychol., 1968, 9, 59-66.

PAGE, M. M. The social psychology of a classical conditioning of attitudes experiment. Submitted for publication.

SPIELBERGER, C. D., \& DE NIKE, L. D. Descriptive behaviorism versus cognitive theory in verbal operant conditioning. Psychol. Rev., 1966, 73, 306-326.

TAFFEL, C. Anxiety and the conditioning of verbal behavior. J. abnorm. soc. Psychol., 1955, 51, 496-501. 